rev.relac.int.estrateg.segur.9(2):183-203,2014

\title{
LA SEGURIDAD HUMANA Y LOS PROBLEMAS COLATERALES DEL AGUA*
}

\author{
José Luis Cadena Montenegro** \\ María Fernanda Ramírez Soler ${ }^{* *}$
}

\section{RESUMEN}

La seguridad humana se refiere fundamentalmente a la obligación que los gobiernos tienen de asegurar la

Este artículo es parte de la investigación geopolítica de los recursos estratégicos, perteneciente al grupo Geopolítica y Economía de la Universidad Santo Tomás.

** Geógrafo y politólogo colombiano, profesional en Ciencias Militares; magíster en Ciencia Política, Universidad de Los Andes; magíster en Planeación Socioeconómica, Universidad Santo Tomás; magíster en Geografía y Ordenamiento Territorial, Universidad Pedagógica y Tecnológica de Colombia; Doctor en Geografía, Universidad Nacional Autónoma de México, especialidad en Geopolítica. Expresidente de la Asociación Colombiana de Geógrafos - ACOGE; miembro de la Asociación Americana de Geógrafos - AAG; miembro del Instituto de Política y Democracia, Brasil; catedrático de la Universidad Santo Tomás de Colombia, director del Grupo de Investigación en Geopolítica y Economía, consultor internacional en Defensa y Seguridad. Correo electrónico: jlcadenam@yahoo.com.

*** Economista y profesional en estadística, Universidad Santo Tomás. Ha estado a cargo de investigaciones como la Muestra Mensual Manufacturera que se realiza en el Departamento Administrativo Nacional de Estadística - DANE. Actualmente hace parte del equipo temático de la Encuesta de Desarrollo e Innovación Tecnológica y de los módulos de Tecnologías de la Información y las Comunicaciones en el DANE. Correo electrónico: maferamirezs@gmail.com. 
supervivencia, los medios de vida y la dignidad de sus ciudadanos. La solución de problemas que afectan la población es función de los Estados, en especial los relacionados con servicios públicos que permitan mejorar la calidad de vida. El acceso deficiente al agua potable se ha convertido en la segunda causa de muerte infantil del planeta. Estudios actuales muestran que 1,8 millones de niños mueren al año como consecuencia de graves problemas de salud derivados del consumo de agua insalubre. El presente artículo tiene como objetivo delimitar los alcances del concepto de seguridad humana, avanzando hacia la problemática en cuanto al uso y abastecimiento del agua en el mundo, y la situación que enfrenta Colombia como potencia hídrica de cara la conservación de los páramos y otras fuentes de recursos hídricos, como también en la prestación del servicio de agua potable.

Palabras clave: seguridad humana, políticas públicas, agua, pobreza.

\title{
HUMAN SECURITY AND COLLATERAL WATER PROBLEMS
}

\begin{abstract}
Human security basically refers to the obligations that governments have for guaranteeing survival, the means of life and the dignity of their citizens. The solution of the problems that affect the population is function of the States, especially those connected with the utilities that permit improvement of life quality. The meager access to drinkable water has become the second cause of children mortality in the planet. Current studies show that 1.8 million children die every year as consequence of the vast health problems that arise from the consumption of unfit to drink water. The purpose of this paper is to delineate the concept of human security, describing the problems related to the use and supply of water in the world and finally bring up the Colombia situation as a hydric power, and its management of water resources such as moors and rivers, as well as the provision of potable water services.
\end{abstract}

Keywords: human security, public policies, water, poverty.

\section{SEGURANÇA HUMANA E OS PROBLEMAS COLATERAIS DA ÁGUA}

\section{RESUMO}

A segurança humana refere-se, essencialmente, à obrigação dos governos de garantir a sobrevivência, subsistência e a dignidade dos seus cidadãos. A solução dos problemas que afetam a população é uma função dos Estados, particularmente os que estão relacionados com os serviços públicos que possibilitam melhorar a qualidade de vida. O escasso acesso à água potável tornou-se a segunda maior causa de mortalidade infantil no mundo. Estudos atuais mostram que 1,8 milhões de crianças morrem a cada ano como consequência de sérios 
problemas de saúde por consumir água contaminada. O objetivo deste artigo é o de definir o alcance do conceito de segurança humana, direcionando-o para o problema do uso e fornecimento de água no mundo e a situação que enfrenta a Colômbia como potência hídrica com vistas à conservação da Região dos Páramos e de outras fontes de recursos hídricos, bem como o fornecimento de água potável.

Palavras-chave: segurança humana, política pública, água, pobreza.

\section{INTRODUCCIÓN}

Al consultar documentos sobre temas ambientales relacionados con la sustentabilidad, se advierte que, desde hace algún tiempo, la expresión seguridad humana aparece cada vez con mayor frecuencia. Seguramente se debe a que la Organización de Naciones Unidas - ONU, ha empleado este término para designar un concepto muy importante, desde finales de la última década del siglo XX. Este ensayo, consecuentemente, pretende contribuir a la socialización del término y al conocimiento de la temática vinculada con los nuevos paradigmas de la seguridad, dilucidando algunas de las principales connotaciones y aspectos relacionados, en particular con relación a su aplicación en América Latina y concretamente en Colombia. Para la UNESCO (2005), "...la seguridad humana es un proceso por el que se crean las condiciones de la dignidad del ser humano"1.

Finalizada la primera década del siglo XXI, los seres humanos no están en situación de riesgo, solamente cuando son amenazados con armas letales. También lo están en aquellas ocasiones en que padecen hambre o enfermedades, o cuando por diversas circunstancias se ponen en riesgo aspectos primordiales de su vida cotidiana y su espacio vital, a sabiendas de que este es el mínimo geográfico requerido para su supervivencia. Entre estas contingencias relacionadas con su propia existencia se mencionan la violación de los derechos humanos y de los principios democráticos, la violencia, los conflictos, el terrorismo, el cambio climático, el deterioro ambiental y la contaminación de la atmósfera, el agua y la litósfera. También se pueden mencionar otras como carencia de alimentos aptos y necesarios, enfermedades y epidemias, desempleo, migración forzada, inseguridad laboral, pobreza, analfabetismo y falta de vivienda.

La seguridad humana debe entenderse como una condición o situación que supone un cambio de perspectivas u orientación y en la que se valore al mundo tomando como núcleo de referencia a las personas, más allá de consideraciones relacionadas con la seguridad estatal.

1. A modo de "definición de trabajo" de la seguridad humana, se suele citar su objetivo primordial, que apunta a la expectativa de "salvaguardar las vidas humanas de las amenazas críticas dominantes y es consistente, en cierto modo, con la realización de las personas en el largo plazo". 
Se trata de una idea-fuerza multiforme, aplicable en diversos contextos sociales, que asocia e incluye las diferentes condiciones para el pleno desarrollo humano. Según este novedoso concepto interdisciplinario, la seguridad se fundamenta primordialmente en la promoción y protección de los derechos de la ciudadanía que garantizan el bienestar y la satisfacción de las personas en el marco de la propia sociedad, más que en el esquema convencional del fortalecimiento del Estado y la defensa armada de sus instituciones ante posibles amenazas, intimidaciones o asechanzas internas o externas.

La seguridad humana implica, además, dar a las personas seguridad contra amenazas u obstáculos violentos y no violentos. Obviamente, el concepto es amplio, complejo y general debido a que las instituciones internacionales y nacionales y los gobiernos han abordado este tema desde diferentes perspectivas y sus notas distintivas y asuntos prioritarios dependen, en cierta medida, de las características particulares y de la realidad predominante en cada región. Los países del Tercer Mundo son los más necesitados de la aplicación de este nuevo concepto.

En diferentes eventos, y en razón a que la seguridad humana resalta aspectos comunes y nexos entre los derechos humanos y el desarrollo de la sociedad, el concepto ha sido incorporado a importantes debates y acuerdos sobre asuntos ambientales, particularmente vinculados con la sustentabilidad y el desarrollo sustentable. Conviene destacar también que, ante la significación del concepto, las Naciones Unidas establecieron, a partir de 2004, una Unidad de Seguridad Humana en su Oficina de Coordinación de Asuntos Humanitarios. La prestación de servicios públicos eficientes es parte importante de la dignidad humana.

Expertos asistentes al Foro Mundial del Agua se han reunido en varias oportunidades para debatir la escasez del recurso en el mundo, que es el mayor desafío que enfrenta la humanidad en la actualidad, pero millones de personas todavía carecen del mismo, problema que podría agravarse debido al rápido crecimiento de la población y al cambio climático. La ONU ha advertido que a medida que el planeta se caliente y se seque, podríamos presenciar conflictos y guerras por causa de este recurso vital.

\section{SEGURIDAD HUMANA}

La seguridad humana es una ampliación del concepto clásico de seguridad, y surgió en el año 1994 en un informe realizado por el Programa de las Naciones Unidas para el Desarrollo PNUD, titulado "Informe sobre el desarrollo humano". En el segundo capítulo de este informe, titulado "Nuevas dimensiones de la seguridad humana", se plantea que después de finalizada la Guerra Fría, los conflictos entre países disminuyeron y se volvieron comunes los conflictos al interior de los mismos (PNUD, 1994). La idea central consiste en llevar a segundo plano el concepto de seguridad, entendida como conflicto entre países, y asumir en primer lugar a las personas, estas últimas como objetivo principal, no solo asegurando la soberanía del Estado, sino ampliando la seguridad a otros ámbitos (Bertrand, 2008). 
El término seguridad humana, se ha construido a partir de la discusión y profundizacion en temas como la seguridad, las paz, los conflictos y el desarrollo económico, tareas iniciadas en el siglo XX, casi una década antes del informe del PNUD, a partir de nuevas ideas formuladas por autores como Thomas (1987) y Tickner (1992), quienes plantearon desde la década del ochenta, cómo la seguridad tambien se podía mencionar para hacer referencia a situaciones donde a las personas no se les brindaba lo necesario para la subsistencia, e incluso, en el caso de Tickner, se usó el término seguridad para hacer referencia a temáticas feministas (Armiñon, 2006). Antes del informe del PNUD se generaron tres ideas a las cuales se puede atribuir la aparición del concepto de seguridad humana: "a) La seguridad humana debe centrarse en las personas; b) la seguridad de las personas se ve amenazada no solo por violencia física, sino tambien por otras amenazas a su subsistencia en condiciones de dignidad", y "una tercera referida a los medios: la seguridad no puede alcanzarse mediante la confrontación y las armas, sino mediante la cooperación y la política" (Armiñon, 2006, pp.62-63).

A nivel mundial, el sentido de la seguridad humana ha dado un importante vuelco, cambiando la concepción clásica de seguridad como algo inherente al Estado. En cambio, ahora se refeiere a una seguridad multidimensional, la cual incluye dentro de sí toda una gran variedad de factores que afectan la seguridad de las personas, como tener un empleo, alimentos, vestuario, vivienda, educación, servicios públicos, salud y generar proteccion para las personas ante amenazas como la pobreza, el cambio climático, la discriminación, las epidemias, los desastres naturales y antrópicos, la escasez, entre otras amenazas al bienestar humano (Cadena, 1999) ${ }^{2}$.

Es de este modo como la seguridad ha dejado de ser un tema que le corresponde a cada país, dependiendo de la situación de su soberanía y conflictos que requieren intervención militar, y ha pasado a abarcar todos los aspectos de la vida humana, dejando aparte las fronteras nacionales e integrando lo local con lo global, considerando que los derechos y la dignidad humana son inherentes a todos los ciudadanos del mundo. Actualmente, el objetivo de la seguridad humana se orienta a disminuir las amenazas para los derechos, la seguridad y la vida (Pereira, 2005).

Aunque son muchos los aspectos que abarca la seguridad humana en su enfoque amplio, los teóricos del tema, y también el PNUD, han establecido siete categorías que comprenden en gran parte las amenazas a la seguridad humana, estas son: la seguridad económica, la seguridad alimentaria, la seguridad en materia de salud, la seguridad ambiental, la seguridad personal, la seguridad de la comunidad y la seguridad política. Por razones de espacio y tiempo, en el presente ensayo nos dedicaremos a tratar uno de los temas relacionados con la seguridad en materia de salud, específicamente el tema del agua a nivel global, regional y nacional.

2. La problemática de los desastres ha dejado de ser una preocupación ocasional de los pueblos y los gobiernos; se ha convertido en un elemento vital en la lista de cuestiones que competen a toda la humanidad, ya sea por su impacto en el desarrollo global, o porque su solución solo se obtiene con esfuerzos sistemáticos prolongados. 


\section{SITUACIÓN DEL AGUA EN EL MUNDO}

Según el Programa de las Naciones Unidas para el Medio Ambiente (PNUMA, 2007) del total de la superficie terrestre, un $70 \%$ está compuesta por agua; de ese $70 \%$ un $97,5 \%$ es el agua que se encuentra en los mares, y el otro 2,5\% es agua dulce, de ese 2,5\% solo un 1,6\% es de fácil acceso humano para consumo y utilización, de ese 1,6\%, según la UNESCO (2009), 70\% es utilizado para riego agrícola, el $20 \%$ sirve a la industria y el resto es para uso doméstico y producción de electricidad (10\%).

El problema de la contaminación del agua a nivel mundial ha generado un cambio en la concepción del término recurso renovable, a no renovable; esto se debe en parte a la insostenibilidad de la contaminación y consumo humano del recurso, siendo el aumento de la población mundial un fuerte agravante de la situación (Foronda, 2008). Cada día se depositan aproximadamente dos millones de toneladas de desechos en las fuentes de agua del mundo y los países industrializados son los que más desechos depositan. Un $90 \%$ de las aguas residuales y un $70 \%$ de los desperdicios industriales son arrojados a los afluentes de agua ${ }^{3}$ por esos países, generando un grave impacto sobre las fuentes de agua potable, que a su vez se convierte en un riesgo para la salud humana (UNWATER, 2010).

La calidad del agua, el acceso a ella y a los servicios de saneamiento ${ }^{4}$ son medios para mejorar la calidad de vida de las personas, de tal forma están estrechamente relacionados con asuntos de carácter socioeconómico, como la pobreza y la insalubridad. Por esta razón se ha planteado dentro de los objetivos de desarrollo del milenio MDG, que para el año 2015 se pueda reducir a la mitad la cantidad de personas a nivel mundial que no tienen acceso a los servicios de saneamiento y agua potable, objetivo que para este momento se encuentra aún distante por el vertiginoso crecimiento de la población, estimando que para el año 2015 ya existirán 2400 millones de personas sin servicio de saneamiento. Es conveniente afirmar que aún hay 1100 millones de personas en el mundo que no tienen acceso al abastecimiento de agua (UNWATER, 2010) (Gráfico 1).

Los problemas de escasez y calidad del agua se han convertido en un tema de interés mundial, ya que el consumo de este recurso se ha triplicado desde el siglo XX, como también se ha incrementado la contaminación del mismo, por lo tanto, su disponibilidad es cada vez es menor. De las grandes fuentes de agua, las que más sobresalen son las de Asia, continente que cuenta con el 36\% de agua potable sobre el total mundial (Gráfico 2); sin embargo, la contaminación de sus fuentes ya es muy elevada.

3. En hidrología, se le denomina afluente de agua a un río que no llega de manera directa al mar, sino que desemboca en otros ríos de mayor dimensión. También recibe el nombre de tributario, y el lugar en el que se une se llama confluencia.

4. El saneamiento básico hace referencia a prácticas en manos de las autoridades oficiales, las cuales implican el servicio de alcantarillado, suministro de agua y tratamiento de residuos sólidos (Rojas Chávez; Gutiérrez \& Soto, 2002). 


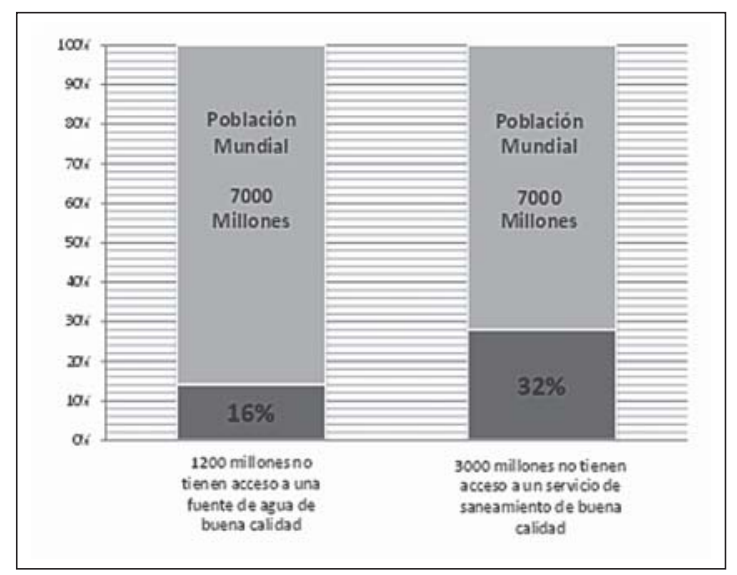

Gráfico 1. Acceso restringido al agua y servicios de saneamiento. Fuente: Elaboración propia con datos de UNWATER, 2010.

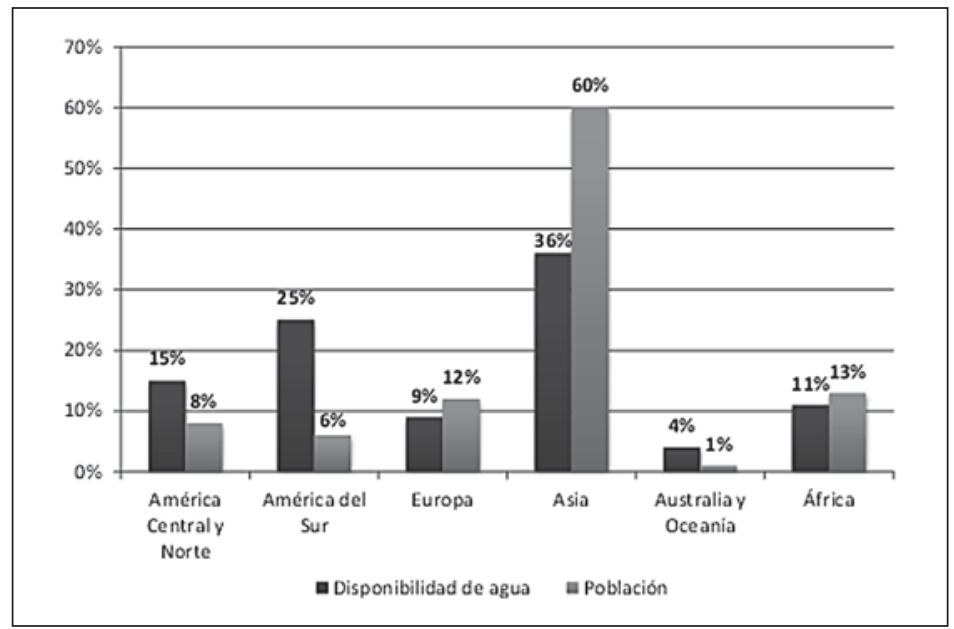

Gráfico 2. Distribución de la población mundial y la disponibilidad de agua por regiones. Fuente: Sánchez \& Sánchez Torres, 2004.

Para el caso de China, el $78 \%$ de sus ríos ya no contienen agua potable, y solo ocho ciudades de la India tienen un sistema completo de tratamiento de aguas residuales. América Latina es el segundo continente con mayor disponibilidad de agua sobre el total mundial, contando con tan solo un $6 \%$ de la población global, pese a lo cual, este continente parece seguir los mismos pasos de Asia, ya que más del $90 \%$ de sus desechos son arrojados directamente a las fuentes de agua potable (PNUMA, 2009). En la actualidad, la contaminación de los cuerpos de agua se constituye en uno de los mayores problemas contra el cual luchan los ambientalistas y se prevé que si no se logra controlar a corto plazo, los efectos pueden ser irreparables. 


\section{SITUACIÓN DEL AGUA EN AMÉRICA LATINA}

América Latina es una de las regiones que cuenta con mayor cantidad de recursos hídricos y fuentes de los mismos. Según el PNUMA (2010), el subcontinente tiene aproximadamente el $31 \%$ del agua dulce a nivel mundial, el 39\% del total de recursos hídricos, el $23 \%$ de las cuencas transfronterizas ${ }^{5}$ y 64 acuíferos $^{6}$. Sin embargo, no todos los países que hacen parte de esta región tienen agua en las mismas proporciones; los países de Sur América y Centro América son los que reciben menos agua proveniente de la lluvia, como también son las zonas con menor cantidad de población las que cuentan con mayor volumen de agua, como las cuencas del Amazonas y el Orinoco (CEPAL, 2002).

Las diferencias en disponibilidad del recurso hídrico son muy marcadas en toda la región, teniendo en cuenta que cada país, dentro de sí, tiene diversidad de climas, que van desde tropicales hasta desérticos, el $6 \%$ de la región está compuesta por desiertos y las grandes fuentes de agua se concentran espacialmente (CEPAL, 2002).

A pesar de las diferencias en la distribución interna del agua, se estima que "cada uno de los habitantes de América Latina y El Caribe contaría con la posibilidad de usar anualmente mayor volumen de agua per capita que el resto de las personas del planeta" (PNUMA, 2010, p.109). Países como Brasil, Honduras, Costa Rica, Guatemala, Panamá y los del sur del continente, tienen grandes fuentes de agua, con las cuales podrían asegurar el servicio de toda su población, a diferencia de zonas como las Antillas, donde el acceso depende de las aguas lluvias, ya que la mayoría de sus fuentes de agua dulce están en contacto con agua salada.

Aunque es evidente la abundancia del recurso en América Latina, el acceso al mismo sigue siendo insuficiente; al menos 150 millones de habitantes de la región no tienen la posibilidad de consumir agua de buena calidad y 250 millones no tienen servicio de saneamiento (UNEP, 2003). La situación empeora cuando se hace una subdivisión entre áreas urbanas y rurales, pues para el 2006 solo la mitad de la población rural de la región tenía acceso al servicio de saneamiento, mientras que la población urbana se acercaba al 90\% de cobertura (Gráfico 3).

Del 5\% más pobre, solo un $40 \%$ tiene servicio de saneamiento, y en países como Haití, antes del terremoto de 2010, el servicio de agua potable abarcaba el $20 \%$ del presupuesto de las familias. En zonas rurales de la región, donde habita el 25\% de la población, el servicio de

5. Las cuencas geográficas son zonas donde el agua cae por precipitación y se escurre a un mismo lugar, ya sea un río, lago o mar. Cuando la zona que abarca la cuenca se ubica entre dos o más países, se le llama cuenca transfronteriza.

6. Los acuíferos son formaciones geológicas subterráneas que almacenan agua como la que proviene de la lluvia. El agua de los acuíferos es considerada agua potable y se puede usar para el consumo humano. 
saneamiento solo llega al 48\% de las personas (UNEP, 2003). Esta situación implica problemas de salubridad que afectan directamente a la población infantil.

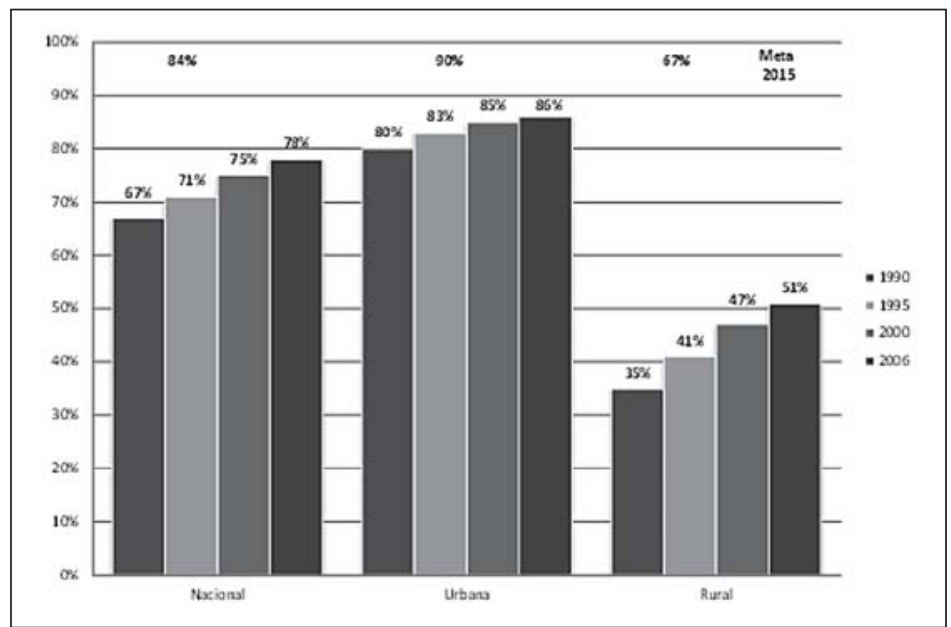

Gráfico 3. América Latina y El Caribe (países seleccionados): población con acceso a servicios de saneamiento, 1990, 1995, 2000 y 2006* (en porcentajes de la población total)

Fuente: Elaboración propia con datos de Naciones Unidas, 2010.

* Comprende los siguientes países: Argentina, Bahamas, Barbados, Brasil, Chile, Colombia, Costa Rica, Cuba, Ecuador, El Salvador, Estado Plurinacional de Bolivia, Granada, Guatemala, Haití, Honduras, Jamaica, México, Nicaragua, Paraguay, Perú, República Dominicana, Saint Kitts y Nevis, Trinidad y Tobago y Uruguay.

Las tarifas que se pagan por el consumo del líquido, en América Latina, sobrepasan el costo que tiene el mismo servicio en países desarrollados (Gráfico 4), siendo la población más pobre la que debe disponer un mayor porcentaje de sus ingresos para acceder al vital recurso; esas tarifas se han elevado en los últimos años por la presencia de multinacionales en el sector de servicios públicos (Lynn, T. \& Schmitter, P., 1991). Esas son las paradojas de nuestra región, tan rica en biodiversidad y tan pobre en dirigentes y hacedores de políticas públicas ${ }^{7}$.

En algunos países, como Argentina, El Salvador y Ecuador, el 20\% de la población más pobre, es decir, la que cuenta con ingresos inferiores a un dólar diario y, por lo tanto, está en condiciones de pobreza extrema, debe disponer de más del 10\% de sus ingresos para acceder al servicio

7. Ante las nuevas realidades, ni los movimientos nacionalistas ni los Estados actuales muestran capacidad de ofrecer apropiadas alternativas en la medida en que el eje sobre el cual giran unos y otros se sustenta en viejas ideas y conceptos que en lo político giran en torno a la idea del Estado nacional y la independencia, aun sabiendo que independencia significa control real y autodeterminación, aspectos estos que en la mayoría de los Estados desaparecieron hace varios años frente al poder económico de empresas de alcance transnacional. 
de agua; en el caso de Colombia, uno de los más ricos en el recurso a nivel mundial, esta cifra se encontraba en el 8\% para el año 2003 (Gráfico 5). Por el contrario, en países como Reino Unido, disponer de más del $3 \%$ del ingreso para el pago de este servicio ya se considera como un indicador de exclusión (PNUD, 2006) ${ }^{8}$.

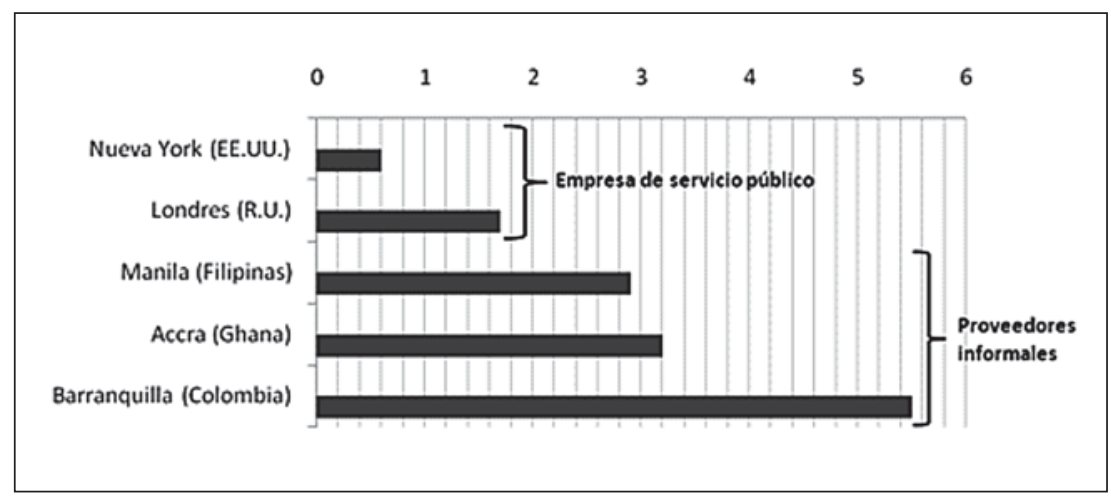

Gráfico 4. Precios del agua. Diferencias en las tarifas entre usuarios ricos y pobres. Fuente: PNUD, 2006.

En la mayoría de los casos, las personas que no tienen acceso al agua potable por medio de redes públicas deben pagar más por la misma, al surtirse a través de intermediarios y, de esa manera, se ven sometidos a un incremento del costo por encima del valor por el cual es suministrada a la población que sí está conectada a la red pública de abastecimiento. En ciudades como Lima, en Perú, o Barranquilla, en Colombia, las personas que no están conectadas a la red pública de abastecimiento llegan a pagar hasta 10 veces más por el recurso. En las grandes ciudades de América Latina existen las favelas, tugurios, cinturones de miseria, casas de hojalata y cartón que tienen el mismo significado y que explican las desigualdades sociales en un continente que, bien administrado, debería ser el granero de la humanidad.

8. Bolivia incluyó en su constitución la relevancia del acceso al agua potable como un derecho humano y no como una mercancía. Ya desde el preámbulo de su constitución se menciona la importancia de dejar atrás las guerras por agua y dar un nuevo paso hacia la protección de los derechos de los ciudadanos en este aspecto. Desde el artículo 16 ya se empieza a dar cabida y relevancia a la importancia del agua, donde se afirma que "toda persona tiene derecho al agua y a la alimentación". Siguiendo con esta misma lógica, en el artículo 20, se determina que "El agua y alcantarillado constituyen derechos humanos y no son objeto de concesión ni privatización", anulando de esta manera el uso del agua para fines lucrativos, y asignando su distribución al Estado. Como también se hace relevancia no solo al servicio de agua sino también al de alcantarillado (Asamblea Constituyente de Bolivia, 2007). 


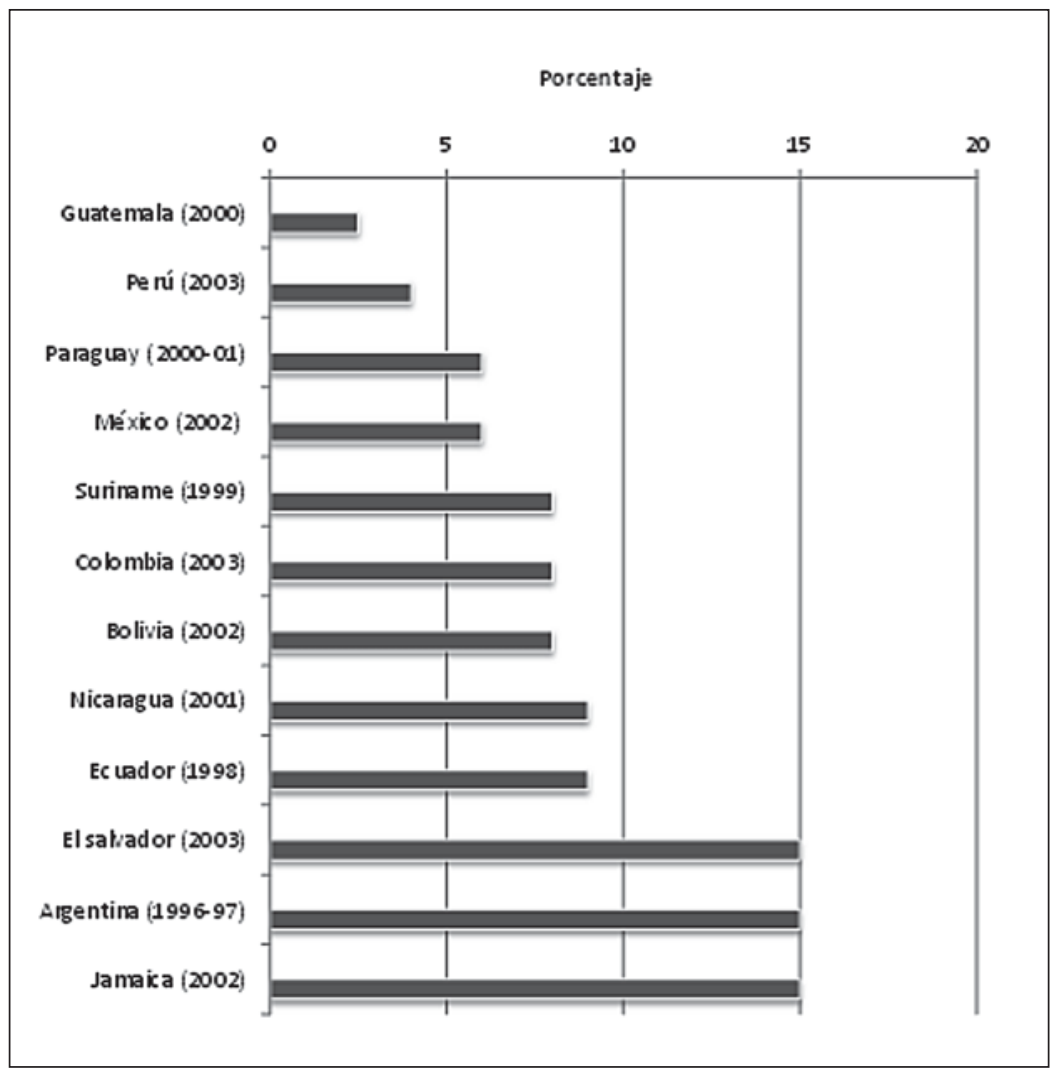

Gráfico 5. Costes del agua para el 20\% de la población más pobre Fuente: PNUD, 2006.

Además de los problemas para el acceso al recurso hídrico, es insostenible el manejo que se le da en América Latina a las aguas contaminadas; en la mayoría de la región al menos el $87 \%$ de los desechos humanos y provenientes de la agricultura, minería e industrias son retornados a las corrientes de agua y mares, sin ningún tipo de tratamiento (UNEP, 2003). Esto significa un grave daño al ecosistema, y a fuentes de agua potable, como también un problema de salubridad, ya que la población puede estar consumiendo agua contaminada con químicos provenientes de la actividad agrícola, industrial o minera. Solo en el caso del secano mediterráneo de Chile todos los pozos de agua para consumo humano están altamente contaminados con coliformes fecales ${ }^{9}$, entre otro tipo de bacterias (PNUMA, 2010).

9. Los coliformes fecales son microorganismos similares a las bacterias que se trasmiten por medio de los excrementos, ya sean humanos o de otros animales. Este tipo de bacterias, en condiciones normales, se consideran inofensivas, pero en algunas situaciones pueden ser seriamente dañinas y producir la muerte. 
Del mismo modo, la situación de las aguas costeras, de donde proviene el suministro de peces para la alimentación y comercialización, está igualmente condicionada a la situación de derrames de aguas contaminadas a los mares. Los peces que consumen los pobladores de las áreas costeras, habitan en aguas contaminadas. Permanentemente los estudiosos del tema están encontrando peces con enfermedades desconocidas, al parecer producto del consumo de substancias tóxicas reconocidas como cancerígenas.

\section{SITUACIÓN DEL AGUA EN COLOMBIA}

Colombia fue considerada como potencia hídrica a nivel mundial, por lo que desde el siglo XX ocupaba el cuarto puesto debido a su alta disponibilidad de agua por habitante en comparación con otros países. Sin embargo, como consecuencia de diversos factores como el crecimiento demográfico y el incremento en el uso de agua para suplir las actividades productivas, para el año 2008 Colombia había descendido del cuarto puesto al 24 (IDEAM, 2008).

En Colombia, según el Ministerio de Ambiente, Vivienda y Desarrollo Territorial, existen aproximadamente 737.000 cuerpos de agua, y la escorrentía ${ }^{10}$ anual del país se calcula en 57.000 kilómetros cúbicos, de los cuales, 2084 kilómetros cúbicos se encuentra en las redes fluviales, dentro de las que se calcula un caudal de 67.000 kilómetros cúbicos.

A pesar de la gran capacidad de abastecimiento de agua del país, la distribución del recurso es heterogénea siendo las regiones menos pobladas las que cuentan con menor disponibilidad. Se estima que más del $80 \%$ de las poblaciones urbanas en Colombia se suplen del recurso a partir de fuentes pequeñas como arroyos o riachuelos, mientras que regiones como la Orinoquia, Amazonia y la del Pacífico, cuentan con la mayor escorrentía. Sin embargo, son las regiones con mayor concentración urbana las que se dedican a actividades productivas que demandan mayores volúmenes. Lo más grave es que el país no tiene la cultura del reciclaje de aguas ni de reutilización del líquido en actividades que no requieran condiciones de potabilidad. Por fortuna, Colombia es un país rico en páramos y fuentes diversas de agua ${ }^{11}$.

Los páramos son ecosistemas indispensables para Colombia ${ }^{12}$, tanto que es poseedora del $64 \%$ de los mismos a nivel mundial (Castaño, 2002), los cuales solo se encuentran en algunos países

10. Escorrentía se entiende como el agua que proviene de la lluvia o la nieve derretida que se moviliza arrastrando consigo sedimentos hasta llegar a los ríos, arroyos, riachuelos y similares. En algunos casos son causa de desastre natural por deslizamientos del terreno.

11. En Colombia existen 1'291.425 hectáreas de paramos húmedos, 86.425 hectáreas de paramos secos y 65.575 hectáreas de superpáramos, estos se clasifican según su altura, clima, vegetación, entre otras características propias del ecosistema.

12. Los páramos, también conocidos como "fábricas de agua", son ecosistemas sensibles que se caracterizan por sus temperaturas extremas y alta humedad; se encuentran en montañas con picos demasiado altos, en estas zonas no 
de América Latina, entre ellos Venezuela, Costa Rica, Perú y Ecuador, siendo Colombia la que tiene mayor número y extensión de los mismos. El país dispone de 14.434 kilómetros cuadrados, lo que equivale al 1.3\% del territorio nacional, como se muestra en el Gráfico No.6 (Ministerio de Ambiente Vivienda y Desarrollo Territorial, Corporación Autónoma Regional de Cundinamarca, Instituto de Hidrología, Meteorología y Estudios Ambientales \& Conservación Internacional Colombia, 2002).

Cuadro 1. Extensión de los páramos en América Latina con relación a la extensión de cada país.

\begin{tabular}{lccc}
\hline \multirow{2}{*}{ País } & $\begin{array}{c}\text { Extensión país } \\
\mathbf{k m}^{\mathbf{2}}\end{array}$ & \multicolumn{2}{c}{ Extensión páramo } \\
\cline { 3 - 4 } & 1.141 .500 & $\mathbf{K m}^{\mathbf{2}}$ & $\%$ \\
\hline Colombia & 249.080 & 14.434 & 1.3 \\
\hline Ecuador & 1.296 .500 & 4.200 & 0.3 \\
\hline Perú & 914.100 & 3.986 & 0.4 \\
\hline Venezuela & 51.200 & 80 & 0.2 \\
\hline Costa Rica & $\mathbf{3 . 6 5 2 . 3 8 0}$ & $\mathbf{3 5 . 3 0 2}$ & \\
\hline Total & & &
\end{tabular}

Fuente: Congreso Mundial de Páramos, 2002.

Los páramos tienen tres funciones relevantes: la producción de agua, la regulación del ciclo hidrológico ${ }^{13}$ y el control del calentamiento global mediante la retención del carbono atmosférico. Los páramos recogen la lluvia y a través del fenómeno de la evapotranspiración ${ }^{14}$ regulan el ciclo hidrológico, se convierten en los nacimientos de la gran mayoría de los sistemas fluviales de la región y de las fuentes de agua potable y para riego. En ciudades como Bogotá y Quito el abastecimiento de agua depende básicamente de los páramos, como también el agua para riego e hidroeléctricas, es decir, que la seguridad alimentaria y la salubridad dependen

es posible la formación de bosques, su vegetación es escasa comparada con otro tipo de ecosistemas, sin embargo, la vegetación del páramo es única y endémica, por lo tanto, su extinción significaría una gran pérdida de especies únicas en el mundo.

13. El ciclo hidrológico es el proceso del movimiento continuo del agua en el plantea, las moléculas de agua pueden pasar por diferentes estados, ya sea hielo, vapor o líquido, antes de retornar a su estado inicial.

14. La evapotranspiración comprende los procesos de evaporación y transpiración de las plantas, mediante el cual el agua que se encuentra en la tierra, y parte de la que se encuentra en las plantas, regresa a la atmósfera en forma de vapor, reiniciando en ciclo hidrológico. 
de estos ecosistemas, a los cuales no se les presta ni la atención ni el cuidado necesarios (De Bievre, Íniguez, \& Buytaert, 2006). En los últimos años, estos ecosistemas han sufrido el embate del hombre que, al romper la frontera agrícola, está utilizando las alturas para siembra de productos vegetales y, en especial, de especies para su transformacion en narcóticos.

A pesar de las grandes fuentes y reservas que Colombia tiene en recursos hídricos, en el país existen 14.4 millones de personas que no tienen abastecimiento de agua seguro y están en riesgo de escasez, y al menos 20 millones de personas, es decir, el 43.8\% de su población está en riesgo futuro de perder la seguridad en el abastecimiento de agua. Solo el $52 \%$ de los municipios cuenta con el servicio de agua las 24 horas. Nueve millones de colombianos no tienen servicio de acueducto y 13.5 millones aún no tienen el servicio de alcantarilladlo; solo 17 municipios cuentan con el servicio de acueducto y alcantarillado con una cobertura del 95\%. El país no cuenta con un manejo completo de aguas residuales, 43\% de estas llegan a los ríos o afluentes de agua sin ningún tipo de tratamiento, esto explica que la mayoría de las muertes por enfermedades derivadas del consumo de agua sean por diarrea y enfermedades colaterales. Además, se estima que los grupos más vulnerables, como los indígenas y los afrodescendientes, no alcanzan a recibir ni la cobertura promedio del país (Defensoría del Pueblo, 2010). Sin embargo, Colombia es uno de los países que en el mundo invierten más recursos en pertrechos militares que en cualquier otro renglón.

El agua en el país se usa en mayor proporción para el riego agrícola (54\%), en segundo lugar para el uso doméstico (29\%), un 13\% se emplea en el sector industrial, un 3\% se usa en el sector pecuario y tan solo un $1 \%$ en el sector de servicios. Las ciudades que generan mayor demanda de agua para el uso doméstico son las principales: Bogotá, Medellín, Cali, Barranquilla y Cartagena. De esas cinco ciudades, solo cuatro alcanzan la mayor demanda de agua para el sector industrial; se exceptúa Cartagena.

Respecto a la calidad del agua que fluye a través de los ríos, las zonas con mayor contaminación se presentan en el río Bogotá, el río Páez, el río Cauca, el río Sogamoso, el río Meta y el río Magdalena, entre otros. La situación es crítica en el caso del río Bogotá, el cual transporta al año 300 millones de toneladas en sedimentos ${ }^{15}$. El grado de contaminación de los ríos y afluentes de agua se puede explicar debido al escaso tratamiento de las aguas residuales; la mayoría de estas se devuelven a los afluentes cercanos a los centros urbanos sin ningún tipo de tratamiento, como se puede observar en el Gráfico 6.

En el siglo XX, antes de la década del 90 la situación del agua fue concebida como servicio público responsabilidad social del Estado, al punto de que en el artículo 365 de la Constitución

15. Entiéndase sedimentación como la materia sólida que después de haberse mantenido flotando se moviliza al fondo del cuerpo de agua por motivo de la gravedad. En la mayoría de los casos, la sedimentación está relacionada con el mal uso del suelo y movimientos de tierra por acciones naturales antrópicas, en todo caso dañinas para el medio ambiente. 
Política Nacional de 1991 se establece que "los servicios públicos son inherentes a la finalidad social del Estado", concibiéndose como un deber de este asegurar su prestación eficiente a todos los habitantes del territorio nacional. Sin embargo, fue el gobierno el que, a través de la Ley 142 del 11 de julio de 1994, se liberó de la responsabilidad de apoyar esta función social, dando origen a su vez a la libertad de competencia en el sector de agua potable, lo que dificulta las condiciones de existencia de las empresas estatales, las cuales debieron enfrentarse no solo con la problemática socioeconómica de la comunidad cada día más pobre sino también con las multinacionales que incursionaron en el negocio del agua, peligro latente a la privatización de este servicio esencial para la vida (Giraldo, 2008).

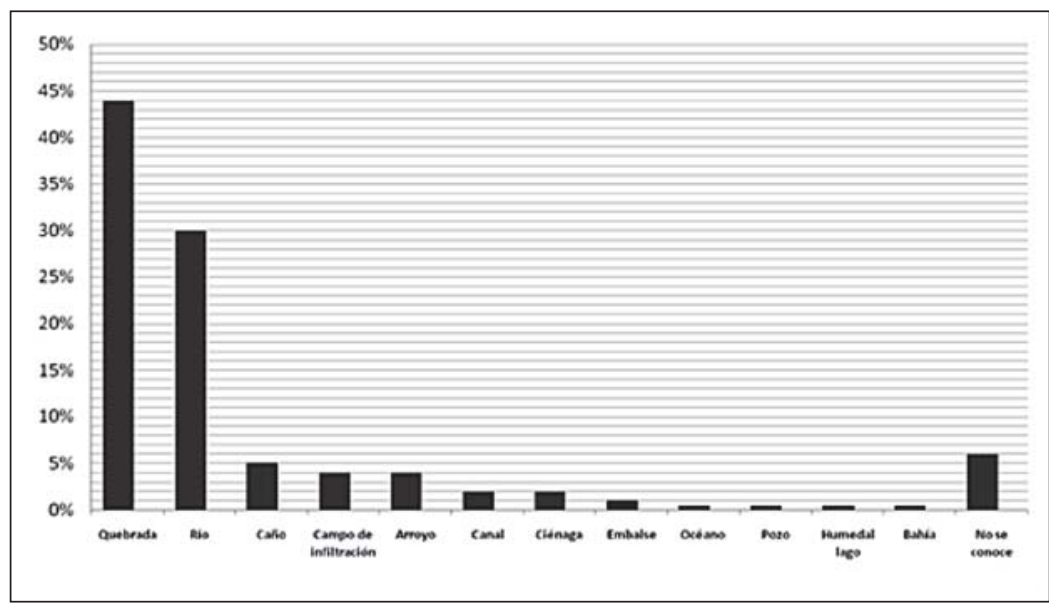

Gráfico 6. Cuerpos de agua receptores de aguas residuales.

Fuente: Ministerio de Ambiente, Vivienda y Desarrollo Territorial, 2010.

Después de la Ley 142, y en razón de la misma, se empezaron a evidenciar aumentos insostenibles en las tarifas del agua, siendo especialmente los pobres los que recibían con mayor dureza tales aumentos, los cuales se encontraban muy por encima del índice de precios al consumidor. Por ejemplo, para el caso de Bogotá, entre los años 1997 y 2002, las tarifas de agua incrementaron así: $232 \%$ en el estrato uno ${ }^{16} ; 138 \%$ en el estrato dos; $110 \%$ en el estrato tres; $59 \%$ en el estrato cuatro, $43 \%$ en el estrato cinco y $39 \%$ en el estrato seis. Este incremento también se dio en otras ciudades del país, de las cuales las 18 principales presentaban aumentos en las tarifas que

16. Los estratos en Colombia son medidas por medio de las cuales se busca clasificar las viviendas de los habitantes según la calidad del entorno y los materiales utilizados para la construcción de las mismas. Esta clasificación tiene como finalidad identificar las viviendas más pobres para otorgarles subsidios. Los estratos se clasifican del uno al seis, y aunque su aplicación se hace invocando el principio de solidaridad, en realidad constituyen un abuso porque el Estado descarga su responsabilidad sobre los trabajadores de mayores ingresos (Mallarino, 2008). 
se encontraban entre $38 \%$ y $226 \%$. No obstante, el aumento en las tarifas es muy significativo si se tiene en cuenta que entre 1998 y 2001 el índice de precios al consumidor a nivel nacional en promedio se encontraba en el 28\% (Contraloría, 2004; en Giraldo, 2008, p.103).

Debido a la alarmante situación generada por el incremento de las tarifas en los servicios de agua, tanto la Contraloría General de la República como la Corte Constitucional se pronunciaron ante tal situación. La Corte Constitucional expidió la Sentencia C-150 de 2003, mediante la cual se buscaba dar mayor prevalencia a la neutralidad y transparencia, como también a la eficiencia económica por encima de la suficiencia financiera.

También, la Comisión de Regulación de Agua Potable y Saneamiento Básico - CRA, por medio de la Resolución 287 de 2004, logró suprimir de las facturas de los usuarios cobros que hacían las empresas de acueducto por conceptos ajenos a la prestación del servicio, como por ejemplo, el cobro de las pensiones de jubilación, la depreciación de edificios, plantas, túneles, entre otros, los cuales eran cargados deliberadamente a las cuentas de los usuarios inflando los costos muy por encima del valor del servicio en flagrante abuso. Con esta modificación, la Superintendencia calculó que las tarifas podrían reducirse del 3\% al $24 \%$, dependiendo de la capacidad de la empresa. El agua, un recurso de primera necesidad, se convirtió en Colombia en un pretexto para que empresas nacionales y extranjeras se enriquecieran de manera logarítmica, logrando que los usuarios pagaran incluso los servicios asistenciales y seguridad social de sus gerentes y empleados. Es la mejor muestra de lo que no deben permitir los legisladores en ninguna parte del planeta: el enriquecimiento de unos pocos con las necesidades de las mayorías.

El servicio de agua en Colombia sigue dependiendo en un 54,6\% de empresas privadas, las cuales buscan principalmente aumentar sus márgenes de utilidad, como también en un $0,2 \%$ de organizaciones autorizadas, las cuales son pequeñas prestadoras del servicio de acueducto y alcantarillado en zonas como las veredas. Las empresas industriales y comerciales del Estado - EICE cuentan con un 44,4\% del mercado de acueducto, mientras que el 0,8\% restante corresponde a los municipios, los cuales prestan el servicio de manera directa. Es así como el servicio de acueducto es prestado en mayor proporción por empresas privadas (Superintendencia de Servicios Públicos, 2009).

El Estado colombiano, para tratar de mitigar la desigualdad en la facturación del servicio de agua, empleó la misma Ley 142 de 1994, con el fin de subsidiar los servicios de acueducto, aseo y alcantarillado para los estratos uno, dos y tres. Estos subsidios, según el artículo 99 de la Ley 1151 de 2007, no podrán ser mayores al 70\% para el estrato uno; 40\% para el estrato dos y $15 \%$ para el estrato tres. Para compensar tales subsidios se establecieron los aportes solidarios, establecidos en el artículo Tercero del Decreto 057 de 2006, expedido por el Ministerio de Ambiente, Vivienda y Desarrollo Territorial, en el que se genera un sobrecosto o aporte solidario en las facturas de los habitantes de estratos cinco y seis, como también 
para las empresas comerciales e industriales; tal aporte solidario se establece de la siguiente manera: $60 \%$ para los usuarios de estrato seis; $50 \%$ para los usuarios de estrato cinco; $20 \%$ para empresas comerciales y $30 \%$ para industriales. Esta fue una decisión unilateral del Estado que nunca consultó a los usuarios de los estratos cinco y seis, su disposición para hacer esos aportes (Republica de Colombia: Municipio de Lérida, Tolima, 2010) ${ }^{17}$. No es cierto que las leyes sean buenas por ser leyes, y en algunos casos, a unos los protegen y a otros los perjudican.

Según la Superintendencia de Servicios Públicos "los mayores consumidores son los usos no residenciales, y es particular observar que los estratos subsidiados consumen el 63\% de toda el agua facturada, lo cual se explica no solo por la gran concentración de personas que habitan en viviendas clasificadas en estos estratos, sino también por la aplicación de subsidios que reducen el precio que paga el suscriptor final por su consumo, y genera incentivos para elevar el mismo", en comparación con los usuarios de estrato cinco y seis, los que, en conjunto, consumen tan solo 3\% del agua facturada, como se puede ver en el Gráfico 7, ya que están obligados a pagar el aporte solidario, generando un sobrecosto en su consumo e incentivándolos a economizar agua, utilizándola de manera más sostenible (Superintendencia de Servicios Públicos, 2009, p.32).

Se observa que los habitantes de los estratos uno, dos y tres, en su mayoría, no tienen una cultura del cuidado y regulación en el consumo de agua; "la situación reflejada en el periodo analizado, generó alertas en cuanto al balance entre los subsidios y contribuciones facturados, el cual generalmente es deficitario, es decir, las contribuciones no alcanzan a cubrir los subsidios requeridos, por lo que se debe hacer uso de otro tipo de recursos para que se completen los subsidios establecidos por ley para los estratos uno, dos y tres, reduciendo así los dineros necesarios para incrementar la cobertura y elevar la calidad del servicio". Esto indica claramente que, a menor pago por el servicio, mayor consumo en los estratos uno, dos y tres, y que los estratos cinco y seis, además de responder por un compromiso que nunca hicieron, son los que menos consumen y más pagan por el solo hecho de estar clasificados como los más pudientes, sin que esto sea verdad en todos los casos.

17. Para sorpresa de los latinoamericanos, un país vecino, Ecuador, ha incluido en su Constitución el derecho al agua de manera categórica. En concreto, en el artículo 12, se determinó que "el derecho humano al agua es fundamental e irrenunciable. El agua constituye patrimonio nacional estratégico de uso público, inalienable, imprescriptible, inembargable y esencial para la vida". En consonancia con esta definición constitucional, desde el inicio, en el Artículo 3 de la Constitución se estableció como el primer deber primordial del Estado "garantizar sin discriminación alguna el efectivo goce de los derechos establecidos en la Constitución y en los instrumentos internacionales, en particular la educación, la salud, la alimentación, la seguridad social y el agua para sus habitantes" (Asamblea Constituyente del Ecuador, 2008). 


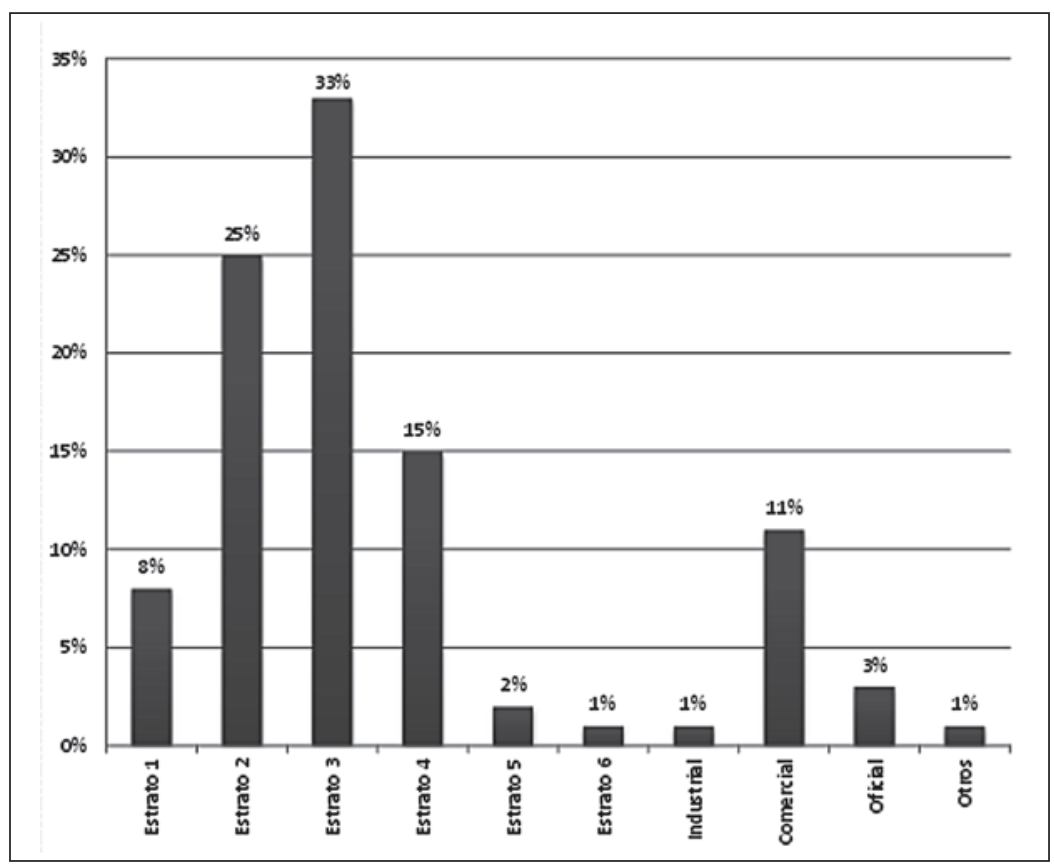

Gráfico 7. Proporción de la facturación por estrato y uso (2007). Acueducto grandes prestadores de servicio ${ }^{18}$.

Fuente: Superintendencia de Servicios Públicos, muestra de 227 prestadores, 2009.

\section{CONCLUSIONES}

Hablar de seguridad humana en el siglo XXI constituye el reconocimiento de la importancia del zoo politikon al que se refería Aristóteles cuando relacionó a la politica como "el arte de gobernar y de redistribuir los recursos". Efectivamente, la humanidad ha entendido que no puede haber nada por encima de sus semejantes y, en tal virtud, en un acto reflexivo de emergencia, pretende otorgar las prioridades a quienes realmente corresponden.

Los estrategas y conductores políticos asumieron el concepto seguridad como algo inherente al pólemos, es decir, a la guerra y sus efectos colaterales; por esta razón, ellos construyeron una catedral del saber a la que no tuvieron acceso quienes no estaban inmersos en el arte de la

18. Los grandes prestadores de servicio son las empresas que tienen más de 2500 usuarios. En América Latina son grandes transnacionales las que se han hecho cargo de asumir la prestación de servicios públicos, homologando los costos por lo alto sin tener en cuenta el poder adquisitivo de los ciudadanos, afectando sobre todo a las clases menos favorecidas. 
guerra. Por fortuna, el nuevo siglo ha permitido ampliar la función de seguridad al cubrimiento de las más elementales necesidades humanas, así como a la defensa de todos los derechos.

Algunos recursos estratégicos como el agua han sido blanco de intereses foráneos que, explotados por transnacionales, han convertido un derecho en un negocio de grandes proporciones, ampliando las asimetrías entre ricos y pobres, siendo estos últimos los que reciben el mayor peso de los costes por un recurso que a nadie debería faltar. Los índices de morbilidad y mortalidad crecen entre la población más pobre en todos los continentes.

América Latina, poseedora de la mayor bioversidad sobre el planeta, afronta problemas de pobreza que no se justifican y que impiden su desarrollo en condiciones sustentables en un mundo globalizado en el que, teóricamente, la oferta y la demanda deciden los movimientos del mercado con miras a mejorar la calidad de vida de más de 800 millones de habitantes. Los recursos naturales han pasado a ser en el nuevo siglo los productos más valiosos para continuar en la carrera del desarrollo tecnológico, supuestamente con la intención de buscar el bien común.

Las políticas públicas en la región, con respecto a la distribución del agua, muestran desinterés por parte de la clase dirigente, aumentando la brecha entre ricos y pobres y generando riesgos para la salud y la vida de sus habitantes. El subdesarrollo en gran parte está relacionado con la ineficiencia en la prestación de los servicios públicos y mientras las políticas públicas no se orienten a reducir la desigualdad económica, el tercermundismo seguirá siendo una realidad.

En Colombia, al igual que en los demás países pobres, la existencia de recursos naturales abundantes en nada beneficia a sus ciudadanos y, por el contrario, esta nación subsiste en la condición de proveedora y exportadora de materias primas. Considerada una de las mayores productoras de agua, afronta problemas de contaminación, ineficiencia en el cubrimiento y mala calidad del líquido para garantizar la vida y salud de sus ciudadanos.

\section{REFERENCIAS}

- Armiñon, K. P. (2006). Seguridad humana: conceptos, experiencias y propuestas. Revista Cidob D'afers Internacionals.

- $\quad$ Asamblea Constituyente de Bolivia (2007). La Paz, Bolivia.

- Asamblea Constituyente del Ecuador (2008). Quito, Ecuador.

- Castaño, U.C. (2002). Colombia alto andina y la significacia ambiental del bioma páramo en el contexto de los andes tropicales: una aproximación a los efectos futuros por el cambio climático global. Bogota, D.C. 
- Bertrand, C.M. (2008). Explorando conceptos: Seguridad humana y construcción de la paz. (FRIDE, Ed.). Recuperado de: http://iidh webserver.iidh.ed.cr/multic/UserFiles/Biblioteca/ IIDHSeguridad /12_2010/7 fdc363d-adf4-4dc3-bb51-e6287757d3b7.pdf. Consultado el 20.2.2011.

- Cadena M., J.L. (1999). Poíticas de planeación urbana frente a los riesgos sísmicos en Santafé de Bogotá, D.C. (tesis de grado para optar al título de Magíster en Planeación Socioeconómica). Santafé de Bogotá, D.C.: Universidad Santo Tomás.

- CEPAl (2002). La sostenibilidad del desarrollo en América Latina y El Caribe: desafíos y oportunidades. México: Naciones Unidas.

- De Bievre, B.; Íñiguez, V. \& Buytaert, W. (2006). Hidrología del páramo. Importancia, propiedades y vulnerabilidad. Páramo.

- Defensoría del Pueblo (2010). Decimoséptimo informe del defensor del pueblo al Congreso de la República. Bogotá, D.C.: Defensoría del Pueblo.

- Farro, M.E. (2008). El agua como derecho humano. El caso de América Latina. El agua, derecho humano y raíz de conflictos.

- Giraldo, N.C. (2008). Agua para consumo doméstico en Colombia. Costos y regulación tarifaria. Gestión y ambiente.

- IDEAM (2008). Informe anual sobre el estado del medio ambiente y los recursos naturales renovables en Colombia: estudio nacional del agua, relaciones de demanda de agua y oferta hídrica. Bogotá, D.C.

- Lynn, T. \& Schmitter, P. (1991). Modes of Transition and Types of democracy in Latin american, Southern and Eastern Europe. En International Social Science Journal, XLIII(2).

- Ministerio de Ambiente, Vivienda y Desarrollo Territorial (2002). Congreso Mundial de Páramos: Tomo II. Corporación Autónoma Regional de Cundinamarca, Instituto de Hidrología, Meteorología y Estudios Ambientales \& Conservación Internacional. Boyacá, Colombia:

- Ministerio de Ambiente, Vivienda y Desarrollo Territorial (2010). Política nacional para la gestión integral del recurso hídrico. Bogota, D.C.

- $\quad$ Pereira, J.P. (2005). Seguridad Humana. (U. A. Barcelona, Ed.) Recuperado de: http://www. tdr.cesca.es/TESIS_UAB/AVAILABLE/TDX-0620106-153920/jcfp1de1.pdf. Consultado el 21.2.2011. 
- Rojas Chávez, R.; Gutiérrez, M., \& Soto, F. (2002). Una metodología para el diagnóstico de un nuevo concepto de saneamiento en el municipio de Santa Cruz Xoxocotlan Oxaca. F.M. Ambiente, Ed.. Recuperado de: http://www.bvsde.paho.org/bvsaidis/mexico13/117. pdf. Consultado el 21.3.2011.

- Sánchez, L. D. \& Sánchez Torres, A. (2004). Uso eficiente del agua. Países Bajos: International Water and Sanitation Centre.

- Superintendencia de Servicios Públicos (2009). Informe anual de servicios públicos en Colombia. Bogotá, D. C.

- $\quad$ PNUD (1994). Informe sobre el desarrollo humano. Nueva York: Oxford University Press.

- $\quad$ PNUMA (2007). Estrategia y política del agua del PNUMA. Panamá.

- $\quad$ PNUMA (2007). Perspectivas del medio ambiente mundial GEO 4: medio ambiente para el desarrollo.

- $\quad$ PNUMA (2010). Perspectivas del medio ambiente: America Latina y El Caribe. Panamá.

- $\quad$ PNUMA (2009). Problemática del agua en el mundo.

- UNEP (2003). Water resources management in Latin America and the Caribbean. Panamá.

- UNESCO (2006). El agua, una responsabilidad compartida. Segundo Informe sobre el Desarrollo de los Recursos Hídricos en el Mundo.

- UNESCO (2009). The United Nations World Water Development Report 3: water in a changing world.

- $\quad$ UNWATER (2010). Clean Water for a Healthy World. 